\title{
LUTO E BANQUETE NO CANTO IV DA ODISSEIA (97-226)
}

\author{
TEOdoro RenNó Assunção
}

Faculdade de Letras da UFMG

\begin{abstract}
Resumo. Este breve ensaio propõe uma tentativa de interpretação das relações de oposição entre luto e banquete na festa de casamento da filha e do filho de Menelau em Esparta (no começo do canto Iv da Odisseia), que se torna um banquete de recepção a Telêmaco e Pisístrato, recém-chegados de Pilos, banquete onde a lembrança por $\mathrm{Me}$ nelau, em conversa com os hóspedes ainda não identificados, dos companheiros dele mortos na guerra de Troia e - especialmente - de Odisseu desaparecido, leva primeiro Telêmaco e depois os outros ao choro e aos gemidos, que são um comportamento típico do luto, mas inconveniente em um tal contexto.
\end{abstract}

Palavras-chave. Luto, banquete, canto Iv, Odisseia.

O TEMA DESTE BREVE ESTUdo SÃo AS RELAÇÕES DE OPOSIÇÃo ENTRE LUTO e banquete (já problematizadas, por exemplo, no diálogo entre Príamo e Aquiles na conclusão da Ilíada) na festa de casamento da filha (com Helena) e do filho (com uma escrava) de Menelau em Esparta, ${ }^{1}$ no começo do canto IV da Odisseia. Esta festa se torna um banquete de recepção a dois hóspedes que acabaram de chegar de Pilos (reino de Nestor): Telêmaco (filho de Odisseu) e Pisístrato (filho de Nestor), banquete que paradoxalmente, pela lembrança por Menelau, na conversa com os dois hóspedes ainda não identificados, dos companheiros de armas mortos em Troia e do desaparecimento de Odisseu, leva primeiramente Telêmaco e depois, quando da retomada por Menelau da lembrança de Odisseu, todos os outros ao choro, ou seja: a uma manifestação de luto (ainda que não haja um cadáver presente ou um

Se lembramos que Menelau, na cena de abertura do canto 4, que apresenta esta festa em andamento, já está enviando sua filha Hermíone para a cidade dos Mirmidões onde reina atualmente o filho de Aquiles (com quem ela irá se casar e em cujo palácio morará definitivamente), podemos inferir que, ao menos quanto à filha, que é a única que Helena pôde lhe dar, esta é uma ocasião de perda para Menelau e, por isso, também de tristeza. Em uma nota que tenta explicar estes contraditórios senso de perda e tristeza (semelhantes aos de um funeral) em uma festa de casamento, Steve Reece 1993, 77, sugere: "This is perhaps related to the historical reality of archaic Greece, where the marriage of a daughter was, from a parent's perspective, tantamount to her funeral, since it involved her 'loss', that is, her removal to another's household (oĩkoc)." 
rito fúnebre propriamente dito). ${ }^{2}$ Estas manifestações de luto suscitam (por sua evidente inconveniência ritual nesta ocasião) a censura de Pisístrato e a insólita retomada da partilha alimentar (e anterior lavagem das mãos), que dão início ao banquete, pelo anfitrião Menelau, assim como suscitam o singular recurso a uma "droga", phármakon, (misturada ao vinho) por Helena, precisamente para cessá-las, possibilitando a continuidade do banquete e um espaço pós-refeição (Telêmaco e Pisístrato então já identificados) para as narrativas de Helena e Menelau sobre Odisseu em Troia, que poderiam, sem os efeitos analgésicos e amnésicos da "droga", novamente suscitar o choro entre estes quatro convivas (direta ou indiretamente implicados nelas).

O fato, aparentemente paradoxal, de que este choro coletivo ocorra no contexto inicial do que é uma festa de casamento torna-se miticamente mais justificável se - a partir da interpretação perspicaz de Robert Schmiel no artigo "Telemachus in Sparta" (Schmiel 1972) - atentamos para o nome

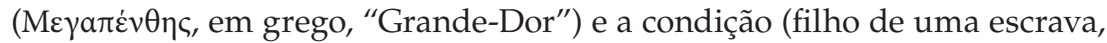

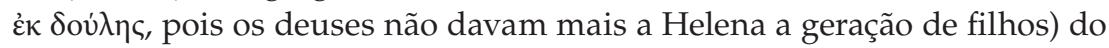
filho de Menelau, como se a sinalizar um problema persistente (que poderia ser conectado à dupla traição de Helena e à separação entre os dois até o fim da guerra de Troia) no casamento de Menelau e de Helena, cuja primeira ruptura (com a transgressão de Páris e Helena, que vão juntos para Troia) - o auditor (leitor) nunca se esquecerá - é o motivo fundamental de toda a guerra de Troia. Esta sugestão negativa discreta será depois confirmada por uma outra (ainda mais sutil), saída da boca de Menelau (Od. 4.207-8), que afirma a "fortuna" (ő $\lambda \beta o v)$ de Nestor, tecida por Zeus, no casamento e na

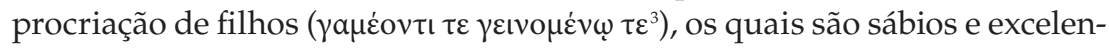

2 Podemos pensar que é justamente a chegada de visitantes inesperados o que desloca definitivamente a atenção da cena da festa de casamento para a cena (já transformada) de um banquete de recepção a um hóspede, onde a conversa entre anfitrião e hóspedes leva quase desapercebidamente a um repertório de temas tristes que despertam reações de luto neste círculo menor de convivas, criando um clima em marcada oposição ao clima de alegria que era de se esperar em uma festa de casamento ou mesmo em um simples banquete de recepção a um hóspede. Steve Reece 1993, 79 (n.15), observa: "The wedding celebrations have been entirely forgotten; they are never again mentioned. This has disturbed some readers. Diodorus the Aristophanean regarded the wedding scene as spurious (Athenaeus, Deipnosophists 180e). Modern scholars [...], by regarding the inherited text here as genuine, have come to appreciate the artistic shift, brought about by the arrival of the two guests, from a wedding scene to a funeral scene (i.e., that of Odysseus), from an

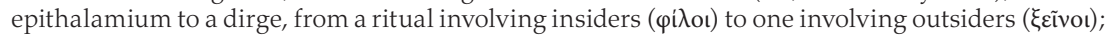
see Bergren 1981, 203-5."

${ }^{3}$ Robert Schmiel $(1972,466)$ comenta assim o sentido deste sintagma (e, mais especificamente, do segundo particípio): "Line 208 presents a problem. Most commentators and earlier translators insist on 'at marriage and at birth', and it must be conceded that the passages they cite tend to indicate that the verb has the active sense 'to bear' in the aorist only. But none of the examples from Homer is a close parallel (the expression is not demonstrably a formula), and the scholiast

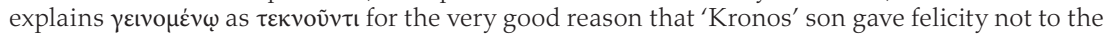
offspring but to the begetter." 
tes na lança, o que (infere-se) não poderia ser dito dele mesmo, casado com uma ex-adúltera e pai de um filho com uma escrava. De maneira mais direta, a estória, depois contada por Menelau, da ação pró-troiana de Helena, então já mulher de Deífobo (seu segundo marido troiano), imitando as vozes das mulheres dos Aqueus em torno do cavalo de madeira para que eles se manifestassem e revelassem fatalmente a emboscada (sendo contidos apenas pelo perceptivo Odisseu, o único que a reconhece), desmente não só a posição pró-aquéia de Helena em sua própria estória sobre Odisseu (que, imitando um mendigo maltrapilho, só é reconhecido por ela, que o acolhe e banha, mas não o denuncia, permitindo o seu retorno e a morte de muitos troianos), mas também o seu então pretenso arrependimento.

Mas se, por um lado, Menelau é, depois de Odisseu, o último a retornar de Troia, tendo, por isso, mais chances de ter uma última notícia sobre ele (e justificando, assim, a viagem de Telêmaco a Esparta, sugerida por Nestor), por outro lado, ele é também um herói que tem uma relação única e diferenciada com a guerra de Troia (não, por exemplo, como a de Nestor), por ter uma consciência aguda de sua responsabilidade por ela e, por isso, uma espécie de grave dívida moral para com os companheiros de armas que lutaram e às vezes morreram por ele, o que é uma retomada odisséica, ajustada a um novo contexto (o do retorno dos heróis aqueus de Troia), de uma caracterização já presente na Ilíada, onde a solicitude e o senso de justiça (mas também um saber sobre os procedimentos pré-jurídicos) são, como bem o repertoriou Philippe Rousseau no artigo "Le deuxième Atride - Le type épique de Ménélas dans l'Iliade" (Rousseau 1990), traços distintivos de Menelau.

Uma tal caracterização pode permitir também em uma maior escala, ou seja: a do conjunto da recepção de Telêmaco por Menelau em Esparta (que parece se estender por aproximadamente um mês: o tempo que leva Odisseu para chegar da ilha de Calipso, passando pelos Feácios, até Ítaca e aí ser recebido por Eumeư ${ }^{4}$, a justificação do excesso de solicitude e gene-

\footnotetext{
${ }^{4}$ Parece-nos pertinente a proposição de Steve Reece $(1993,71-7)$ de que a retomada da situação em Esparta no canto 15 se dá não após o último dia representado no canto 4 (com os relatos de retorno de Menelau, sua promessa de presentes a Telêmaco e o anúncio final de um banquete pelo narrador), em respeito à pretensa incapacidade de Homero de representar a simultaneidade de duas ou duas séries de ações (ou seja: à chamada lei de Zielinski), mas após todo o lapso de tempo que cobre a viagem de Odisseu de Ogígia, passando pelos Feácios, até chegar em Ítaca e ser abrigado por Eumeu, ou seja: após os aproximadamente 30 dias cobertos, no presente da narrativa, pelos cantos 5 a 14. Pois se um tal modelo de descrição de duas ações simultâneas (com a mesma contagem do tempo em dois lugares distintos) é também encontrável em Homero, ele pode estar aqui muito oportunamente a serviço de um tema que atravessa todo o episódio: o excesso de generosidade de Menelau (e o seu desejo de recompensar de algum modo Odisseu, através de seu filho) que acaba por reter inadequadamente o seu hóspede por um tempo talvez maior do que o desejado por este último. Este tema, assim enfatizado por uma longa permanência
} 
rosidade do anfitrião (ironicamente, para o leitor, tematizada por ele mesmo nos versos $71-73$ do canto $\mathrm{xv}$ ) como uma ameaça para a continuidade da viagem (ou o retorno) do hóspede, algo que - como bem o viu Steve Reece no capítulo 4 ("Sparta") de The Stranger's Welcome (Reece 1993, 74-76, 97-99) - é indicado primeiro pelo convite de Menelau (no dia seguinte ao da festa de casamento, ou seja: ainda no canto IV) para que Telêmaco fique mais onze ou doze dias em Esparta (Od. 4.587-89), e mais tarde (um mês depois deste convite, ou seja: já no canto $\mathrm{xv}$ ), quando Telêmaco já lhe sinalizou explicitamente sua pressa em voltar (Od. 15.64-66), será indicado pelo convite inoportuno de Menelau para ele e Telêmaco viajarem a cavalo pela Hélade até Argos de modo a poderem colher muitos presentes de hospitalidade ( $\mathrm{Od}$. 15.80-85), e, enfim, será representado algo caótica e dramaticamente na cena de despedida a Telêmaco, ${ }^{5}$ onde este, com Pisístrato, por sua urgência, atrelam os cavalos, montam no carro e já estão saindo do palácio ("Saíram pelo portão e pelo pórtico ressoante", $O d$. 15.146) quando aparece Menelau que, consciente de suas obrigações rituais, vai desajeitadamente atrás deles, com uma taça de vinho para fazer a última libação (que não chega a ser bem explicitada) e lhes endereçar os votos propícios de felicidade e uma saudação a Nestor (Od. 15.151-3), e sendo, ainda uma última vez, Telêmaco e Pisístrato retidos, já montados sobre o carro e fora do portão, pela aparição auspiciosa de um pássaro (voando do lado direito com um ganso branco nas garras) a qual deve ainda, após a demora de Menelau, ser interpretada por Helena (cf. Od. 15.160-81), para, enfim, eles poderem de fato partir.

de Telêmaco em Esparta, também permite, por outro lado, aproximar os obstáculos ao retorno de Telêmaco daqueles ao retorno de Odisseu em razão da excessiva generosidade de seus anfitriões (Circe, Calipso e Alcínoo), criando uma semelhança temática (segundo o modo de hospitalidade) entre o retardamento do retorno do filho e o do retorno do pai, como bem o viu M. J. Apthorp no artigo "The Obstacles to Telemachus' Return" (Apthorp 1980).

${ }^{5}$ Steve Reece interpreta a aparente inabilidade da indicação do fato de que eles não só já atrelaram os cavalos, mas já montaram sobre o carro e saíram pelo portão do palácio, não dando espaço adequado à última libação e aos votos de felicidade de Menelau (assim como ao prodígio de um pássaro e à sua interpretação), como um reordenamento insólito e intencional dos elementos de uma cena típica de partida para, neste contexto, sinalizar uma última vez o excesso de solicitude de Menelau e sua inadequada retenção de seu hóspede. Ele retoma, assim, a demonstração convincente de Gilbert P. Rose no artigo "Odyssey 15.143-82: a narrative inconsistency?" (Rose 1971), que, no entanto, percebe também no aparente mau arranjo da cena a chance para um justificado elemento cômico ou até mesmo patético na atitude de Menelau, algo com o que Reece não parece concordar inteiramente, mas que nos parece não apenas possível, mas também plausível, uma vez pensado o conjunto do episódio. Para uma posição que considera esta inabilidade (em sentido literal) do narrador como signo da composição oral (neste caso, desajeitada) de uma cena típica ou tradicional a partir de elementos empobrecidos ou comprimidos, ver os artigos de D. Gunn, "Narrative Inconsistence and the Oral Dictated Text in the Homeric Epic" (Gunn 1970), e de M. W. Edwards, "Type-Scenes and Homeric Hospitality" (Edwards 1975). 
No começo da cena de recepção dos dois hóspedes, Menelau (hospitaleiro e atento à reciprocidade) repreende veementemente Eteoneu que hesitava em lhes dar acolhida, reconhecendo que, quando da viagem de retorno, "certamente nós, tendo comido muitos dons de hospitalidade / de outros homens, aqui chegamos" (Od. 4.33-4). Os cavalos são desatrelados, levados para o estábulo e recebem o que comer (em uma cena detalhada que ecoa a da de acolhida de humanos), e - em um modo mais refinado de recepção - os dois hóspedes são banhados, ungidos e vestidos por servas, antes de se sentarem ao lado do anfitrião Menelau (um lugar de honra) e de (segundo um bloco formular típico) receberem a água lustral para as mãos e a preparação da mesa com comida e bebida. Menelau, então, atento à tradição de hospitalidade, os convida a primeiro comer para só depois perguntar por sua identidade (Od. 4.6o-2), e lhes oferece a sua parte de honra ( $\gamma \dot{\varepsilon} \rho \alpha)$ da comida: "um lombo gordo de boi assado".

Mas, depois de eles terem comido e bebido, naquele que seria o momento da identificação, Telêmaco se antecipa e, admirado pela riqueza do palácio, comenta junto à cabeça de Pisístrato, para não ser ouvido, que aquele pátio deve ser como o de Zeus olímpio (Od. 4.74), o que leva Menelau, que o ouviu, a uma correção sensata e modesta da afirmação elogiosa do hóspede, que o faz desviar-se do presente imediato (lembrando primeiro do custo demasiado pesado - por exemplo, a impossibilidade de evitar a morte de Agamêmnon - pela aquisição desta riqueza em suas viagens de retorno, e de seu pouco valor comparado à vida dos companheiros mortos em Troia e, enfim, do quanto em Troia sofreu por ele Odisseu, que agora está desaparecido), e dar forma aqui, em uma micro-escala e segundo o modo ultra-responsável de Menelau, ao padrão narrativo odisséico da identificação ou reconhecimento tardio de um hóspede não nomeado, tal como descrito por Bernard Fenik em "The nameless Stranger", primeiro ensaio da parte I de Studies in the Odyssey (Fenik 1974, 5-60). Vejamos, mais de perto, em uma tentativa minha de tradução, a passagem deste discurso de Menelau que é decisiva para a primeira reação de choro de Telêmaco (ainda não identificado, mas ironicamente, para o leitor, nomeado no fim da passagem) instaurando um clima de luto que não condiz com o do banquete. Ao afirmar que reina, "não se ale-

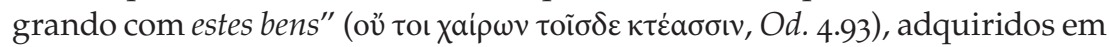
sua longa viagem de retorno, Menelau, após um parêntese, diz (causando o choro e a tentativa de escondê-lo por parte de Telêmaco):

\footnotetext{
"Destes (bens) tendo a exata terça parte, no palácio eu deveria morar, mas os guerreiros estarem salvos, os que morreram então na larga Troia, longe de Argos nutridora-de-cavalos. Mas, no entanto, por todos lamentando e me afligindo muitas vezes, estando eu sentado em nossos salões,
} 
às vezes me deleito no senso com o gemido, outras vezes paro; pois (é) rápida a saciedade do gélido gemido.

A todos não tanto eu lamento, mesmo estando afligido, quanto a um único, que me faz odiar o sono e a comida quando lembro (dele), pois nenhum dos Aqueus penou tanto quanto penou e suportou Odisseu. E por isso, então, era para ele ter sofrimentos, e eu a dor sempre inesquecível por ele, pelo modo como há muito está ausente, e nem sabemos se ele vive ou já está morto. Lamentam-no, de algum modo, tanto Laertes, o ancião, quanto a sensata Penélope, quanto Telêmaco, que ele deixou recém-nascido em casa." Assim falou, e neste, então, suscitou o desejo do gemido pelo pai, e lágrimas das pálpebras para o chão lançou, ouvindo sobre o pai, a manta púrpura diante dos olhos segurando com ambas as mãos. Mas o percebeu Menelau...

$(\text { Od. } 4.97-116)^{6}$

Nesta passagem, Menelau (retrospectivamente reconhecido e solícito) começa admitindo desejar a perda de dois terços de sua riqueza em troca do estarem vivos os companheiros mortos em Troia, em uma reflexão sobre o valor que mobiliza a sua responsabilidade pela guerra, levando-o a um luto genérico por todos os Argivos mortos e, como hipérbole deste luto, a uma brevíssima reflexão gnômica sobre os limites (facilmente alcançáveis) do prazer com o "gélido gemido", em um oxímoro cuja paradoxal verossimilhança é ameaçada por sua incapacidade de sustentar-se por muito tempo. Mas, em uma conexão inteiramente odisséica, a partir do luto genérico por todos os Argivos mortos em Troia, Menelau irá distinguir o luto por Odisseu, explicitando os seus constituintes tradicionais incompatíveis com o banquete (sobretudo o jejum ritual, mas também a ausência do sono, pois ele lamenta, mais do que a todos, a um único "que me faz odiar o sono e a comida", ö $\uparrow \dot{\varepsilon}$

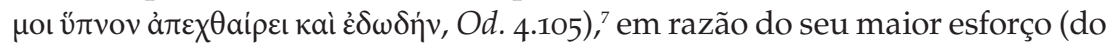

\footnotetext{
${ }^{6}$ Todas as traduções de trechos da Odisseia citados aqui são de minha autoria e visam apenas à uma precisão semântica, sem nenhuma preocupação de encontrar em português um metro único básico como o hexâmetro dactílico homérico, mas tentando sempre conservar a unidade do verso para facilitar a localização do seu conteúdo em grego. O texto grego adotado é o editado por Thomas W. Allen para a coleção de textos clássicos da Oxford (Allen 1987), mas foi consultado também o texto grego estabelecido por Helmut van Thiel e publicado pela Olms (Van Thiel 1991).

${ }^{7}$ É certo que Menelau, assim, evita, por um pudor compreensível nesta situação (e sem o qual ele poderia insinuar manifestamente algo de negativo sobre sua relação com Helena), mencionar uma terceira necessidade orgânica que em Homero é também ignorada no luto: o sexo, que, na descrição por Tétis do luto excessivo de Aquiles por Pátroclo, é pensado, na metonímia da cama e juntamente com a comida (ou o pão), como algo que deve ser retomado, após terminado o trabalho de luto, para que a vida possa continuar: "até quando [...]/ comerás teu coração, não te lembrando nem do pão/nem da cama? Pois é bom justamente isto: com uma mulher se misturar/em amor..." (Il. 24.129-31). Ver para esta questão o meu artigo "Luto e comida no último canto da Ilíada" (Assunção 2004-2005).
} 
que o de qualquer Aqueu) nesta guerra. O poeta (ou a tradição) da Odisseia formula aqui, por meio do luto de suas personagens relativo às estórias sobre a guerra de Troia (ou seja, e sobretudo, a Ilíada, mas também os poemas do Ciclo Troiano que narram o que, ainda no âmbito desta guerra, ocorre antes e depois do que é representado na Ilíada), a ideia de que nenhum guerreiro aqueu foi nesta guerra tão importante (ou - odisseicamente, com a noção do

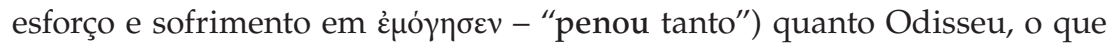
será confirmado por Demódoco na sua terceira canção, que conta a concepção e condução por Odisseu da armadilha do cavalo de madeira, decisiva na tomada de Troia, e sua luta final contra Deífobo, o segundo marido troiano de Helena, colocando em segundo plano Aquiles, o protagonista da Ilíada, morto antes disso, e dando a entender que, em uma disputa entre os dois (como a narrada pela primeira canção de Demódoco e interpretada pelos escoliastas como sendo para definir qual a excelência decisiva na futura tomada de Troia: se a "coragem" de Aquiles ou a "inteligência" de Odisseu ${ }^{8}$ ), o protagonista da Odisseia levaria a melhor. ${ }^{9}$

A reação lutuosa de Telêmaco, aqui esperável não só pela menção do desaparecimento de Odisseu (que é o que motiva a sua busca de informações sobre o pai e presença em Esparta), mas também e ironicamente pela de seu próprio luto por ele, serve como signo (por sua inadequação ao banquete) para uma sua próxima identificação pelo anfitrião Menelau, em uma cena cujo desenho antecipa o das mais detalhadas reações lutuosas de Odisseu ao ouvir a primeira e a terceira canções de Demódoco (ele também chora e cobre o rosto com o manto, sendo percebido pelo anfitrião Alcínoo), que são elementos mais estendidos e em dupla do mesmo padrão narrativo odisséico do retardamento da identificação do hóspede ainda não nomeado (cujo conjunto, no episódio dos Feácios, ganha uma forma bem mais larga e precisa). Mas chama a atenção o fato de que, nos três casos, os discursos que despertam esta reação lutuosa tenham como assunto, o que é bem odisséico, as ações de Odisseu (juntamente com outros guerreiros aqueus) na guerra de Troia, como se a sinalizar que o efeito agora da fama positiva ( $\kappa \lambda \dot{\varepsilon}$ 'c) destas ações guerreiras sobre o seu protagonista (ou sobre um familiar seu, como o filho Telêmaco, ou sobre um companheiro de guerra, como Menelau) é antes

\footnotetext{
${ }^{8}$ Os termos usados pelos escoliastas (em Scholia Graeca in Homeri Odysseam tomus I) para distinguir as formas de excelência de Aquiles e de Odisseu para a captura de Troia são, mais pre-

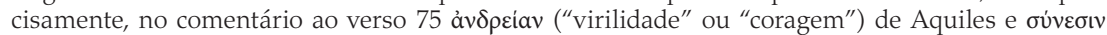
("inteligência") de Odisseu, e no comentário ao verso 77 à $v \delta \rho \varepsilon i ́ \alpha v$ ("virilidade" ou "coragem") de

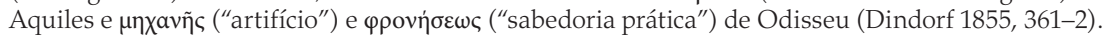

9 Gregory Nagy 1979, 40, sugere o seguinte: "[...] in the first song of Demodokos [...], Odysseus was characterized along with Achilles as 'best of the Achaeans' because one of these two heroes was destined to be the destroyer of Troy. In the epic composition of Demodokos, Odysseus is implicitly 'best of the Achaeans' because tradition upholds his claim to have destroyed Troy."
} 
a tristeza lutuosa e - acrescentaríamos (lembrando o símile, para o segundo choro de Odisseu, de uma mulher que vê o próprio marido sendo morto por inimigos pelos quais será escravizada) - o de um forte sentimento de perda.

Na seqüência desta reação de Telêmaco, enquanto Menelau, que o percebeu chorando, pondera o que fazer, Helena, que vem do quarto ( $\dot{\varepsilon} \kappa$ $\theta a \lambda a ́$ oı o), como se não estivesse participando da festa de casamento, ${ }^{10}$ entra em cena para fiar (uma atividade feminina tradicional) e, antecipando-se a Menelau, intervém com uma fala em que ela reconhece rápido Telêmaco, por sua semelhança com o filho de Odisseu, que o deixou recém-nascido em

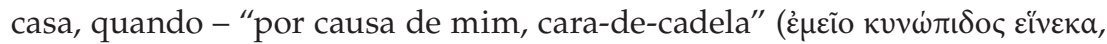
Od. 4.145), esclarece ela, injuriando-se - os Aqueus foram para Troia. Imediatamente depois, Menelau reconhece a semelhança física entre os dois e nota também que ele chorava e escondia o rosto quando ele, Menelau, contava rememorando "quantas coisas aquele (isto é, Odisseu) sofrendo pe-

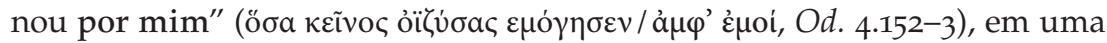
descrição que explicita a sua responsabilidade pela guerra de Troia, assim como, após a intervenção de Pisístrato (que, se identificando como filho de Nestor, confirma a identidade e faz uma breve apresentação de Telêmaco), Menelau dirá, novamente voltando a atenção para Odisseu e se responsabilizando pelo trabalho que lhe deu em Troia: "à minha casa chega o filho de um homem muito amigo, / que por minha causa penou muitas provações" (ö

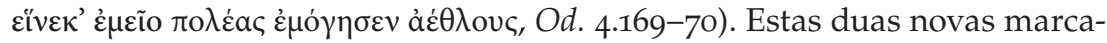
ções de Menelau (que de algum modo ecoam o auto-injuriamento de $\mathrm{He}$ lena) parecem justificar, pelo desejo de compensação e justiça, o excesso de generosidade da sua oferta imaginária a Odisseu de uma das cidades do seu reino espartano, para que eles, mais próximos, pudessem se freqüentar em recepções recíprocas até a morte de um dos dois (cf. Od. 4.176-8o). Mas a impossibilidade desta compensação é afirmada na conclusão deste discurso triste e emotivo de Menelau, que sugere como causa provável desta impossibilidade a inveja de um deus, "que tornou aquele o único desgra-

\footnotetext{
${ }^{10}$ Se pensarmos que, na cena de abertura que apresenta a festa de casamento dos filhos, Me-

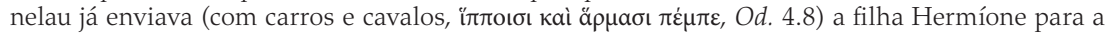
cidade dos Mirmidões, onde reinava o filho de Aquiles (Neoptólemo), podemos supor que a festa que continua é apenas (estando o noivo e a noiva presentes) a de seu filho (com uma escrava) Megapentes, o que poderia muito bem explicar a ausência de Helena até este momento. Stephanie West $(1988,201)$ percebe bem que há algo de estranho neste detalhe em um tal contexto festivo: "The detail of Helen emerging from the privacy of an inner room is a further indication that the wedding party with which the book opened has been forgotten". Enquanto Robert Schmiel (1972, 465), apesar de não fazer uma inferência como a que sugerimos (que supõe uma diversidade de interesses de Helena quanto aos dois filhos de Menelau), também aponta para a estranheza possivelmente significativa deste detalhe: "One wonders why Helen was apparently not present at the wedding celebration for her children. Perhaps one should simply enjoy the grand entrance and not ask embarrassing questions. Or perhaps this is another indication that all is not well in Sparta."
} 


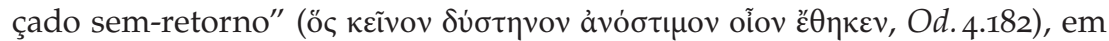
uma descrição hiperbólica que, distinguindo Odisseu pela desgraça, desta vez suscita um choro coletivo entre os quatro (os outros convivas da festa de casamento tendo, há algum tempo, desaparecido da cena):

Assim falou, e nestes todos suscitou o desejo do gemido.

Chorava a argiva Helena, que foi gerada por Zeus,

e choravam tanto Telêmaco quanto o Atrida Menelau,

e nem o filho de Nestor mantinha os dois olhos sem lágrimas;

pois se lembrava no ânimo do irrepreensível Antíloco,

a quem o brilhante filho da Aurora resplendente matou.

(Od. 4.183-88)

Aqui, o foco final em Pisístrato, que prepara a sua próxima fala para Menelau, parece introduzir o tema (já presente na Ilíada 19.301-2, quando do choro de Briseida e outras mulheres por Pátroclo morto) das razões diferenciadas para o choro, mas mantém-se também como horizonte comum para estas manifestações de luto as perdas causadas pela guerra de Troia, neste caso a de um irmão de Pisístrato: Antíloco - o novo escudeiro de Aquiles após a morte de Pátroclo - que, ainda jovem, para salvar seu pai Nestor, foi morto por Mêmnon, filho da Aurora e rei dos Etíopes, em um episódio troiano pós-iliádico que (segundo os resumos da Khrestomatheía de Proclo) era descrito no poema cíclico A Etiópida, atribuído a Arctino de Mileto (cf. Allen 1986, 105-6, "Proculus"). Pisístrato, então, embora reconhecendo a legitimidade desta manifestação de luto (por exemplo, para seu irmão Antíloco, conhecido como um bom corredor e combatente), estranha a sua conveniência em um banquete e sugere que ela seja posposta para o dia seguinte:

e agora, se isto é possível, deixa-te convencer por mim; pois eu não me deleito lamentando depois do jantar, mas também a Aurora nascida-de-manhã está para vir; e não me sinto em nada indignado com o chorar quem dos mortais morra e cumpra o seu destino.

Pois isto também (é) a única honra para os desgraçados mortais: tanto cortar a cabeleira quanto das faces lançar lágrimas.

(Od. 4.193-8)

Os comentadores modernos - seguindo uma divisão já presente entre os

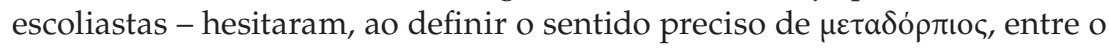
mais literal de "depois do jantar" (como, por exemplo, Ameis-Hentze, Irene de Jong ${ }^{11}$ e nós aqui) e o aparentemente mais plausível de "durante o jan-

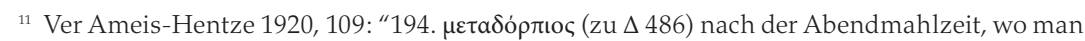
sich geselliger Freude hinzugeben pflegt"; e Irene de Jong 2001, 100: "Pisistratus B (indirect request to change the subject) I don't like weeping after dinner, tomorrow is another day (193b195a)" (negrito meu). 
tar" (como William Stanford e Stephanie West ${ }^{12}$ ). Mas se pensarmos que o momento pós-refeição, tradicionalmente ocupado pela conversação entre os convivas ou pelo canto do aedo, também faz parte do banquete homérico, veremos aqui - no modo mais polido de uma sugestão indireta para que os convivas mudem o comportamento ou também os temas de conversa, como quer Irene de Jong em A Narratological Commentary on the Odyssey (De Jong 2000, 100) - novamente a conjunção negativa entre uma manifestação

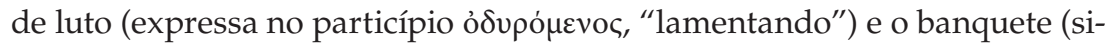

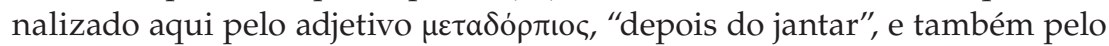

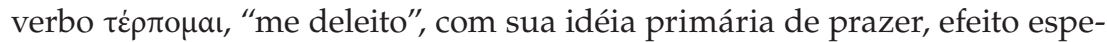
rado neste tipo de ocasião). Se Pisístrato aqui parece retomar uma tradição de luto (negativa quanto ao banquete) já indicada diretamente pelo próprio Menelau ["A todos não tanto eu lamento, mesmo estando afligido, / quanto a um único, que me faz odiar o sono e a comida,/ quando lembro (dele)", Od. 4.104-6], ele irá na seqüência acrescentar, além do não comer e do não dormir (que de algum modo interrompem a continuidade normal da vida), um gesto ritual mais preciso: o corte da cabeleira doada ao morto (cf. Aquiles e outros Mirmidões cobrindo com os cabelos cortados o cadáver de Pátroclo em Ilíada 23.135-6), mas que aqui - na ausência de um cadáver e de um rito fúnebre concreto - dificilmente seria executado. Signos deste luto mais memorialístico (e que se dá como voz não articulada em discurso) continuam a ser neste banquete apenas os lamentos, os gemidos e o choro.

Menelau, então, apesar de advertido por alguém mais jovem, reconhece a sabedoria de suas palavras (que são como as de um homem $\pi \varepsilon \pi v v \mu \varepsilon \dot{v}$ os, "sábio", "de bom senso", e "até mesmo um que seja mais velho",

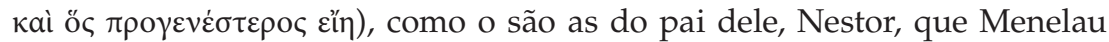
aproveita então para elogiar por sua "fortuna" (ő $\lambda \beta$ ov) "no casamento e na

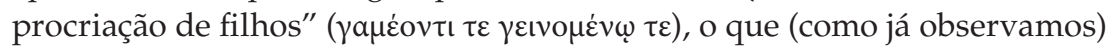
não poderia ser dito dele mesmo, casado com uma ex-adúltera e pai de um filho com uma escrava. E ele passa, então, como anfitrião atento às boas maneiras de mesa, à surpreendente ordem de recomeço do banquete, que terá início com uma outra lavagem das mãos executada pelo servo Asfálion (em grego, “O que não cai”):

"E que nós deixemos a choradeira, que antes aconteceu, e do jantar de novo nos lembremos, e sobre as mãos água eles vertam. Mas estórias já a partir da aurora há de haver

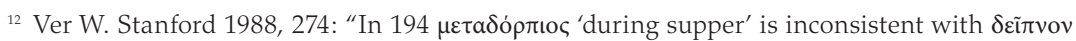

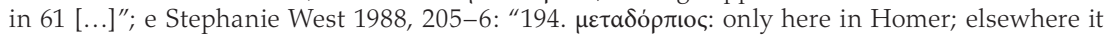
means 'after supper', but 'during supper' is indicated by Menelaus' subsequent proposal to resume their meal, though a listener might well misinterpret the word at first hearing". 
para Telêmaco e eu dizermos inteiras um para o outro."

Assim falou, e então verteu água sobre as mãos Asfálion,

o hábil e prestativo servo do glorioso Menelau.

E eles sobre as iguarias prontas à frente lançavam as mãos.

(Od. 4.212-8)

Se Menelau está aqui, de algum modo, retomando a sugestão de Pisístrato ("aurora", agora no ablativo, ๆ̉ $\dot{\theta} \varepsilon v$, volta a ocorrer), podemos pensar que o choro e as lembranças (como as sobre Odisseu) que o despertaram poderiam ficar para o dia seguinte (como se agora sendo "estórias", $\mu \tilde{v} \theta o$, para serem contadas entre ele e seu hóspede principal, Telêmaco), e a sugestão de atenção direta ao banquete (na fala de Pisístrato, como deleite pós-jantar, $\mu \varepsilon \tau a \delta o ́ \rho \pi ı \varsigma$ )

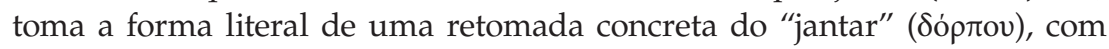
uma primeira e breve ordem de lavagem das mãos. Na execução, que inverte a ordem do que é comandado (cf. De Jong 2001, 100), a descrição desta lavagem, que antecede tradicionalmente a refeição, é sintética (apenas uma larga parte do verso 216, com o detalhe de que aqui a água é vertida diretamente sobre as mãos e não sobre uma bacia de prata, para os comensais se lavarem) e a retomada do jantar se dá, sem nenhuma preparação da mesa e da refeição (pois elas já estariam preparadas), apenas pela retomada do verso formular que descreve o consumo da comida com as mãos (a ser compreendido literalmente, o que justificaria bem, portanto, a cerimônia da lavagem).

Mas o que surpreendeu algumas comentadoras (como Stephanie West e Irene de Jong) é o fato de que esta proposição venha pouco depois (na temporalidade da cena descrita pela narrativa) da refeição (que Menelau nomeia

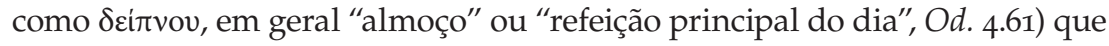
constitui o núcleo do primeiro momento de recepção dos dois hóspedes, descrito pelo narrador com os dois conhecidos versos formulares, que não deixam dúvida quanto à satisfação da fome e da sede: "E eles sobre as iguarias prontas à frente lançavam as mãos. / Mas depois que expulsaram o desejo de bebida e comida..." (Od. 4.67-8). Segundo Stephanie West, em A Commentary on Homer's Odyssey vol. I, a passagem do canto IV que vai do verso 183 a 218 "é danificada por uma contradição com a narrativa anterior, uma vez que a proposição de Menelau de retomar a refeição (213) é incongruente com 68, onde nos é contado que Telêmaco e Pisístrato terminaram de comer".13

Ora, esta pretensa incongruência está sendo percebida a partir de uma verossimilhança pressuposta (segundo um certo padrão realista) que pode não condizer exatamente com os padrões narrativos homéricos. No

${ }_{13}$ West 1988, 205, tradução minha. Já Irene de Jong $(2001,100)$ diz que "a sugestão de Menelau de retomar o jantar (213-214) [...] chega como algo de surpreendente depois do verso formular 68 assinalando o fim de uma refeição (e cf. o $\mu \varepsilon \tau \alpha \delta$ ó $\operatorname{tıoc~de~Pisístrato)"~(tradução~minha).~}$ 
canto IX da Ilíada, por exemplo, quando os embaixadores de Agamêmnon (Odisseu, Ájax e Fênix) chegam à tenda de Aquiles, uma refeição de acolhida é preparada com cuidado para eles (não por servos, mas por Aquiles, Pátroclo e Automedonte) e eles - poderíamos dizer por necessidade ritual ou convenção de hospitalidade - a consomem, segundo a descrição destes mesmos dois versos formulares (Il. 9.221-2), ainda que já tivessem comido há pouco na reunião do conselho de "anciãos" na tenda de Agamêmnon (segundo os mesmos dois versos formulares de Il. 9.91-2), o que, aliás, é tematizado por Odisseu logo no começo de sua fala a Aquiles (Il. 9.225-9), quando diz que eles não estão necessitados do "banquete" ou, mais literal-

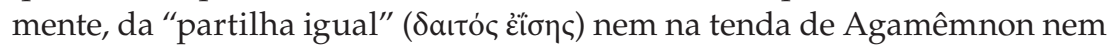
ali (na de Aquiles), havendo muita comida para compartilhar, mas sendo o sofrimento dos Aqueus na atual situação de guerra o que os preocupa de fato. Semelhantemente, no canto xxIV da Ilíada, Aquiles e os companheiros preparam uma refeição para Príamo (cf. Il. 24.621-6) - que será não somente o núcleo do ritual de hospitalidade, mas também um corte do jejum lutuoso prolongado de Príamo - e, novamente por meio dos mesmos dois versos formulares (Il. 24.627-8), podemos supor que participam da refeição juntamente com Príamo e o seu arauto, quando sabemos que, na chegada de Príamo, Aquiles (ao menos) tinha acabado de comer e de beber, estando a mesa ainda a seu lado (cf. Il. 24.475-6).

Nestes dois casos, a sociabilidade básica da refeição enquanto "par-

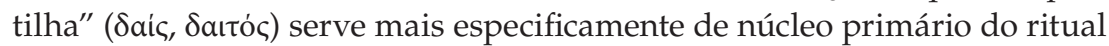
de recepção do hóspede e parece, assim, se justificar não por uma verossímil necessidade de comer (no caso de Odisseu no primeiro exemplo, e no de Aquiles no segundo), mas por uma convenção ritual que coincide também com a convenção das fórmulas narrativas que compõem esta cena típica. No entanto, no canto IV da Odisseia, a primeira refeição de Telêmaco e Pisístrato já cumpriu sua função ritual de primeira acolhida dos hóspedes, sendo ela também um recomeço (proposto pelo anfitrião Menelau) em relação à cena inicial de banquete na festa de casamento do seu filho e sua filha (cf. Od. 4.15-7). Este novo recomeço do banquete por ordem de Menelau (com a lavagem das mãos e o lançá-las à comida pronta em apenas dois versos) teria, portanto, apenas a função ritual de sinalizar um corte do clima de luto (marcado aqui pelo choro, os gemidos e a lamentação) que inadequadamente se instalou no banquete. Por outro lado, ele permite também, recriando uma situação de partilha da comida e da bebida, que Helena tenha a ocasião adequada para misturar o pápuakov (a "droga") no vinho dos convivas. ${ }^{14}$

${ }^{14}$ Ver De Jong 2001, 100: "Menelaus' suggestion to resume dinner (213-214) [...] flows forth from his desire to raise their spirits, and makes it possible for Helen to put a drug in the wine" (negrito 
Uma vez reconhecida a prioridade desta lógica ritual (que impede a conjunção de manifestações de luto e do banquete) na composição desta cena, poderíamos também - dentro do contexto maior de uma história do banquete grego antigo - aceitar a sugestão de Luciana Romeri, no artigo "Platon et la tradition conviviale" (Romeri 2002), de que esta cena pode servir como contra-exemplo homérico à separação marcada, sugerida por Platão no

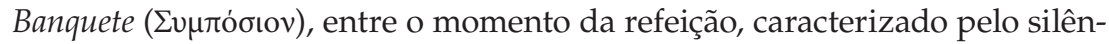
cio (dos convivas e de quem narra), e o momento posterior (apenas do beber vinho com), caracterizado pelos discursos trocados em uma conversa. Mas o mais evidente e talvez único exemplo homérico da continuidade de uma conversa durante o instante mesmo da refeição (ainda que, como no canto IV da Odisseia, a refeição possa ser retomada e a conversa continuar depois) é o do famoso discurso de Odisseu para Alcínoo (no canto vil da Odisseia), se dizendo mortal e, portanto, necessariamente submetido ao estômago ou à fome ( $\gamma \alpha \sigma \tau$ '́ $)$, e pedindo que o deixe comer (cf. Od. 7.208-21), sendo que nesta cena, também de acolhida a um hóspede, após a preparação da mesa e o serviço da comida descritos por um conhecido bloco de versos recorrente (aqui Od. 7.172-6), o narrador descreve o consumo solitário de comida e de bebida por Odisseu como uma ação inacabada (ou seja: por meio do imperfeito e não do aoristo): "Então o brilhante Odisseu que-muito-suporta bebia ( $\pi \tilde{\imath} v \varepsilon)$ e comia $(\tilde{\eta} \sigma \theta \varepsilon) ; "$ (Od. 7.177). Se tomarmos, enfim, o elogio ao banquete (e ao aedo) feito por Odisseu, logo no começo de sua grande narrativa aos Feácios (início do canto Ix), veremos que aí, em uma descrição genérica aplicável também à cena anterior (fim do canto viII) em que Demódoco cantava

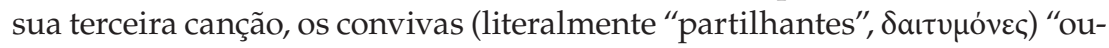
vem o aedo/ sentados em fila, e junto deles estão mesas repletas / de pão

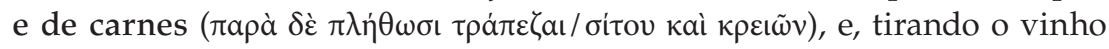
da cratera/ o escanção o leva e verte nas taças" (Od. 8.7-10), sendo de se supor que - ainda que apenas o serviço do vinho seja descrito como uma ação presente - a presença de mesas cheias de comida junto a eles sinalize a possibilidade de retomada do consumo de comida a qualquer momento.

Vejamos, enfim, a ação final de Helena (que antecede o seu relato e o de Menelau sobre Odisseu em Troia) no banquete desta noite em Esparta, para tentarmos compreender melhor o seu sentido:

Aí então outras coisas planejou Helena por Zeus gerada; de imediato lançou no vinho, de que eles bebiam, a droga: a que desfaz dor e cólera, e traz esquecimento de todos males.

meu). Restaria acrescentar que a atitude de Menelau como anfitrião aqui, propondo um recomeço do banquete que irá se prolongar, se coaduna bem com a sua excessiva generosidade e o possível efeito de retardamento da partida do hóspede Telêmaco, tal como sugerido por Steve Reece (1993, 71-7). 
Quem a engolir, uma vez que tenha sido misturada na cratera, durante todo um dia não lançará lágrimas pelas faces abaixo, nem se tiverem morrido tanto a sua mãe quanto o seu pai, nem se bem à sua frente um irmão ou um filho querido forem mortos pelo bronze, e ele com os olhos vir isso.

(Od. 4.219-26)

Nesta passagem (em sua conexão com o que segue) a primeira questão que se coloca é a do modo de definição desta "droga" ( $(\alpha \dot{\rho} \mu \alpha \kappa o v)$, cuja natureza botânica - apesar de bem estabelecida depois a sua proveniência egípcia (onde, segundo o narrador, "todo e cada um é um médico experimentado", Od.4.231) - não é indicada e nem precisada, mas apenas os seus efeitos e, antes mesmo disso, a noção de ambigüidade que o próprio nome grego

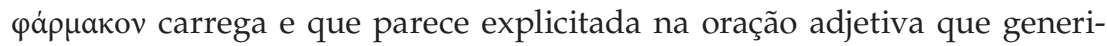

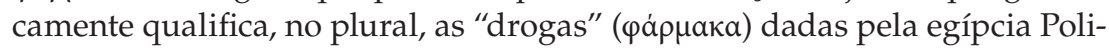
damna (em grego, a "Multi-subjugadora") a Helena: "muitas vezes, quando misturadas, são boas; muitas outras vezes, são maléficas." (Od.4.230). Assim, permanecerá impossível e inútil tentar identificá-la precisamente, sugerindo, como W. Stanford em seu "Commentary", o ópio como a conjectura mais plausível (apesar de ser pertinente a sua observação de que não seria líquida, pois o verbo usado para ela é $\beta a ́ \lambda \varepsilon \varepsilon$, "lançou", e não $\chi \varepsilon \tilde{\varepsilon} \varepsilon$, "verteu", cf. Stanford 1988, 275), ou, como Stephanie West, tentando provar a impossibilidade histórica de um ópio egípcio nesta época (ou mesmo aduzindo o fato de que as primeiras experiências com o ópio são normalmente desagradáveis) e lembrando do uso pelos Egípcios de misturar ao vinho um incenso preparado, chamado kyphi, cujo efeito, segundo Plutarco (De Iside 80), seria o de dissolver a tristeza e a tensão sem embriaguez (cf. West 1988, 206-7).

São, portanto, exatamente os efeitos desta "droga" ( como descritos pelo narrador, o que realmente a define nesta narrativa. Eles são indicados, primeiramente, pelos adjetivos neutros (que a qualificam ou substituem) coordenados por dois $\tau \varepsilon$ e formados a partir de dois prefixos negativos ou privativos ( $v \eta$ - e $\dot{\alpha}-)$ e de dois nomes com noções negativas

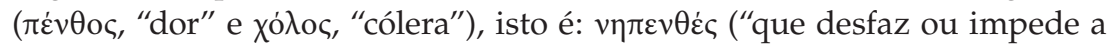

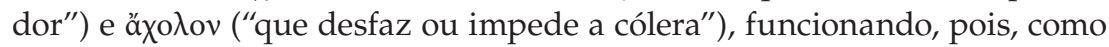
um analgésico (mas aqui não contra uma dor física) e como um calmante que pode apaziguar um sentimento violento. A caracterização seguinte, que é mais genérica e parece englobar as duas anteriores, é formulada também como a negação de algo negativo, ou seja: ela é "o que traz esquecimento

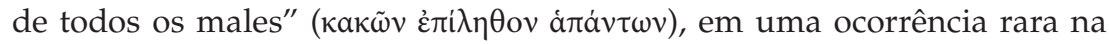
Odisseia do esquecimento (cujo objeto aqui não é, por exemplo, o retorno, mas "todos os males") considerado como algo positivo. Já aqui tanto a dor quanto os males que devem ser esquecidos (a cólera, neste caso, podendo 
ser pensada como dirigida a quem, por exemplo, matou um ser querido próximo) parecem remeter ao tipo de lembrança dolorosa (de todos os companheiros mortos em Troia ou de Odisseu desaparecido) evocada por Menelau e cujo efeito foram as lamentações, os gemidos e o choro.

$\mathrm{E}$, nos quatro versos seguintes, que dão um exemplo genérico hiperbólico do seu efeito sobre um eventual consumidor (precisando as três características apresentadas pelos três adjetivos neutros no verso 221), esta conexão possível com as lembranças dolorosas e fúnebres de Menelau (e seu efeito lutuoso sobre os ouvintes), que formam o imediato contexto anterior, torna-se ainda mais provável. Os dois primeiros versos não só lembram que a mistura com o vinho (e presumivelmente com a água com que este é misturado) se dá no recipiente tradicional para a mistura que é a cratera, onde estaria já o vinho "de onde eles bebiam" (verso 220) e a partir da qual a mis-

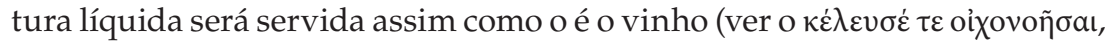
"ela ordenou verter o vinho", do verso 232), como também descrevem o seu efeito prolongado (comparado, por exemplo, ao do vinho), mas pontual, porque limitado a um dia ( $\dot{\varphi} \varphi \eta \mu \dot{p}$ ploc), e, portanto, sem o risco maior de uma transformação duradoura (como a dos companheiros de Odisseu em porcos, após beberem a "mistura", кикє $\dot{v}$, preparada por Circe) ou de uma espécie de adicção fatal (como a dos companheiros de Odisseu que provaram o "lótus"). Este efeito é precisamente o do impedimento das lágrimas: "Quem a engolir, uma vez que tenha sido misturada na cratera, / durante todo um dia não lançará lágrimas pelas faces abaixo..." (Od. 4.222-3).

Mas é a motivação destas lágrimas, apresentada nos dois versos seguintes, que sugere mais fortemente, no modo de uma espécie de hipérbole (porque são os eventos mesmos e não apenas a sua lembrança que as causam), a conexão possível com as lembranças dolorosas de Menelau sobre Troia e seu efeito lutuoso sobre os ouvintes. O verso 224 é mais genérico: "nem se tiverem morrido tanto a sua mãe quanto o seu pai", mas não deixa de lembrar o caso possível de Telêmaco (ou de Orestes), enquanto os versos 225 e 226, que remetem, por exemplo, às posições de Pisístrato e Nestor em relação a Antíloco, definem com mais precisão que esta morte, presenciada

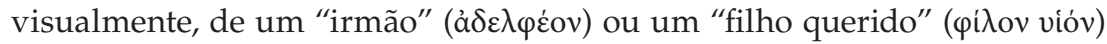
se dá "através do bronze" ( $\chi \propto \lambda \kappa \tilde{\omega})$, ou seja: é uma morte violenta e por arma, cuja ocasião mais provável é uma guerra: "nem se bem à sua frente um irmão ou um filho querido / forem mortos pelo bronze, e ele com os olhos vir isso" (Od. 4.225-6).

Se é, assim, evidente a conexão entre as lágrimas causadas por estas mortes e as causadas pelas lembranças de Menelau (que também remetem a mortes ou desaparecimentos devidos à guerra), o efeito da "droga" ( $\varphi \dot{\alpha} р \mu \alpha \kappa o v)$ de Helena visa também, como a retomada do jantar por Mene- 
lau, a suspender o clima de luto (inadequado ao banquete) suscitado por estas lembranças de Troia e - presume-se pela seqüência - a tornar possível contar e ouvir estórias de Odisseu na guerra de Troia, que, sem a droga misturada ao vinho de que eles bebem, despertariam neles mais uma vez manifestações extremas de tristeza. Portanto, a interpretação, já presente em Plutarco (Quaestiones conviviales 1.1.4, 614c) e Macróbio (Saturnalia 7.1.18) e retomada com perspicácia por Ann Bergren no artigo "Helen's 'good drug'" (cf. Bergren 2008, 116-23), de que a estória de Helena sobre Odis-

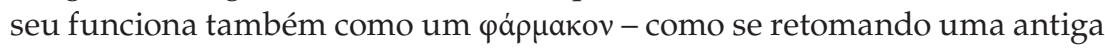
tradição médica do poder encantatório e curativo das palavras - não tem nenhuma consistência neste contexto narrativo preciso, pois é justamente a tristeza que uma tal estória pode despertar (sobretudo em Telêmaco, o hóspede principal) o que este $\varphi$ ápuakov de Helena quer combater ou evitar. ${ }^{15}$

\section{REFERÊNCIAS}

Allen, T. W., ed. 1987a. Homeri Opera tomi III et IV. Oxford: Oxford University Press. 15th impr. (1st ed. 1908).

Allen, T. W., ed. 1987b. Proculi Chrestomathiae Eclogae. In Homeri Opera tomus V, 99109. Oxford: Oxford University Press. 13th impr. (1st ed. 1912).

Ameis, K. F.; C. Hentze. 1920. Homers "Odyssee" für den Schulgebrauch erklärt. Erster Band, Erstes Heft, Gesang I-VI. Leipzig: Teubner.

Apthorp, M. J. 1980. “The Obstacles to Telemachus' Return." The Classical Quarterly 30 (New Series): 1-22.

Assunção, Teodoro R. 2004-2005. “Luto e comida no último canto da Ilíada." Classica (Brasil) 17/18: 49-58.

Bergren, Anne. 2008. "Helen's 'good drug'." In Weaving Truth - Essays on Language and the Female in Greek Thought, cap. 5, 111-130. Cambridge, Mass.: Harvard University Press.

De Jong, Irene. 2001. A Narratological Commentary on the Odyssey. Cambridge: Cambridge University Press.

Dindorf, Wilhelm. ed. 1855. Scholia Graeca in Homeri Odysseam tomus I. Oxonii: E Typographeo Academico.

${ }^{15}$ Dentro de uma tal lógica de uso desta "droga", pode-se, enfim, também arriscar a conjec-

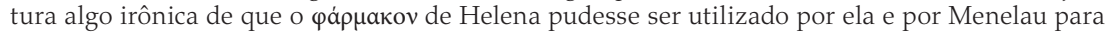
poderem, sem grande tristeza, conversarem sobre a guerra de Troia ou sobre o passado de seu casamento rompido pelo adultério da esposa com o troiano Páris (que é a causa desta guerra), ou - como um tal passado trágico não é de todo apagável - para simplesmente poderem conviver. Ver De Jong 2001, 100: "In principle, all those crying in 183-6 need this drug (even Telemachus, who will hear tales celebrating his father's cleverness, might become emotional, as is Odysseus himself in Book 8), but it seems that Helen and Menelaus, who are still in the grip of their past, need them most" (negrito meu). 
Edwards, M. W. 1975. "Type-Scenes and Homeric Hospitality." Transactions of the American Philological Association 105: 51-72.

Fenik, Bernard. 1974. "The nameless Stranger." In Studies in the Odyssey (Hermes Einzelschriften, Heft 30), 5-60. Wiesbaden: Franz Steiner Verlag.

Gunn, D. 1970. "Narrative Inconsistence and the Oral Dictated Text in the Homeric Epic." American Journal of Philology 91: 192-203.

Nagy, Gregory. 1979. The Best of the Achaeans. Baltimore: The Johns Hopkins University Press.

Reece, Steve. 1993. "Sparta (Od. 4.1-624; 15.1-184)." In The Stranger's Welcome: Oral Theory and the Aesthetics of the Homeric Hospitality Scene, cap. 4, 71-99. Ann Arbor: The University of Michigan Press.

Romeri, Luciana. 2002. "Platon et la tradition conviviale." Revue des Études Anciennes 104 (1-2): 51-9.

Rose, Gilbert P. 1971. "Odyssey 15.143-82: a narrative inconsistency?" Transactions of the American Philological Association 102: 509-14.

Rousseau, Philippe. 1990. "Le deuxième Atride - Le type épique de Ménélas dans l'Iliade." In Mélanges Pierre Lévêque 5, 325-54. Besançon: Presses de l'Université de Besançon.

Schmiel, Robert. 1972. "Telemachus in Sparta." Transactions of the American Philological Association 103: 463-72.

Stanford, W. B. 1988. "Commentary." In The Odyssey of Homer vol. 1: Books I-XII. London: Macmillan. (First edition: 1948).

Van Thiel, Helmut. ed. 1991. Homeri Odyssea. Hildesheim: Olms.

West, Stephanie. 1988. "Books I-IV." In A Commentary on Homer's Odyssey vol. I, Books I-VIII, eds. A. Heubeck; S. West; J. Hainsworth, 49-245. Oxford: Oxford University Press.

Abstract. This essay is an attempt to give an interpretation to the relations of opposition between grief and banquet at the wedding reception of Menelaus' daughter and son's marriages in Sparta (in the beginning of Odyssey's book iv), which becomes an occasion of hospitality for Telemachus and Pisistratus, that have just arrived from Pylos, an occasion where, during a conversation with the still unknown guests, the Menelaus' recollection of his dead companions in the Trojan War and, particularly, of the lost Odysseus leads Telemachus (followed by the others) to weep and cry, which is typical behavior of grief but inappropriate for that occasion.

Keywords. Grief, banquet, Odyssey, book Iv. 